\title{
DEVELOPMENT OF TRANSBOUNDARY NETWORKING PATTERN OF COMMUNITY-BASED TOURISM IN UBON RATCHATHANI PROVINCE (THAILAND)
}

\author{
P. SOMNUEK ${ }^{1}$ \\ ${ }^{1}$ Department of Tourism and Hospitality Innovation, Faculty of Liberal Arts, \\ Ubon Ratchathani University, Thailand.
}

\begin{abstract}
This study aimed to find (1) the establishment of a Community-based tourism (CBT) network in Ban Sai Moon and Ban Phosri in Ubon Ratchathani province, Thailand, and (2) an assessment of the established CBT network developed by the two communities. In this study, participatory action research and data derived from a total of 60 samples (30 from tourism representatives in the two communities and 30 from visitors), chosen by simple random sampling, were applied for the collection of data. Methods applied for data analysis included: focus group discussion, participatory observation, and KM. The findings demonstrated that different strengths (S), weaknesses $(\mathrm{W})$, opportunities $(\mathrm{O})$, and threats (T) were found in the two communities, based on the community context, community member lifestyles, and tourism attractions. These differences could be appropriately utilized as individual/unique tourism resources providing CBT activities and participatory CBT itineraries. Secondly, community networking management comprised the following steps: studying internal community contexts and conditions, searching for village leaders, promoting an awareness of associations and networks, developing activities and relationship levels, enhancing information systems, promoting cognitive processes among networks, summarizing lessons learned, and expanding the CBT networks. Lastly, regarding the strength assessment, it was indicated that the former management focused on individual management, resulting in poor negotiation power to present diversified and interesting tourism programs for visitors. Conversely, a community organization was established as a network information center to manage tourism resources and connect tourism and community development appropriately. Therefore, villagers could employ their resources to show a variety of tourism services, resulting in increased benefits in the areas.
\end{abstract}

Keywords: community-based tourism (CBT), development of networking patterns, Phosri community, Saimoon community, transboundary tourism management.

\section{INTRODUCTION}

Community-based tourism (CBT) is considered an alternative tourism management form, administered by a community for its greater benefit. It involves sustainable tourism development, consistent with globalization and focusing on self-responsibility and self-reliance [1]. CBT is directly supported by the Thai government, in order to promote and enhance communities in all regions of the country, especially the northeastern area (ESAN), which hosts plenty of tourism destinations and identical folk living styles.

The Thailand CBT institute [2] reported that, in the province of Ubon Ratchathani, CBT was found in many communities, managed by their own village leaders and consisting of two situations: (1) a drive for tourism from community management, assisted by several organizations, and (2) a drive for tourism and CBT establishment from tourism research studies supported by the Thailand Research Fund. In an earlier period, CBT in Ban Saimoon and Ban Phosri were founded by an academic service project for the development of tourism in the 2014-2015 fiscal year at Ubon Ratchathani University.

Vilairat and Boonsa-ard's study [3] revealed that Ban Saimoon had a variety of potential tourist attractions, and its village leaders supported tourism activities by granting 
opportunities for villagers to organize activities consistent with their capabilities. Ultimately, the community was considered strong, harmonious, and ready to arrange CBT activities in the near future. The office of Ubon Ratchathani Community Development [4] indicated that Ban Phosri had become an effective community regarding CBT management and that there was a satisfactory level of support from its village leaders. Several occupational groups were also found in the village, such as the Rice Placement Group, Cultural Performance Group (Local Drum), and Herbal Therapy Group. In addition, villagers were permitted to organize similar CBT activities to those of Ban Saimoon, so that the community would be an interesting CBT destination. However, many tourism attractions located in these areas were unknown, resulting in undeveloped infrastructure.

It was, therefore, inspiring to study the development of CBT transboundary networking patterns, to eliminate existing problems in the two communities, which lie eight kilometers apart. The developed CBT networks could enhance strong powers of negotiation and increase sustainable tourism alliances. Networking development could be determined by establishing a wide variety of tourism destinations connected with tourists' needs and establishing a fair distribution of benefits to the villagers [5]. The results of the study could be applied to establish an effective tourism network, and it might become a best practice in CBT transboundary networking patterns for Ubon Ratchathani, the northeastern region, or even at the national level.

\section{OBJECTIVES OF THE STUDY}

This study had two objectives: the establishment of a CBT network in the areas concerned and an assessment of the established CBT network.

\section{LITERATURE REVIEW}

\subsection{Community-based tourism (CBT)}

CBT was closely connected to ecotourism but more concerned with the participation and involvement of local people, along with the associated costs. Consequently, CBT was more people-centered, community-orientated, and resources-based than ecotourism. The idea behind CBT was to establish effective empowerment of the community, enhancing their involvement in decision making, and ensuring that the will and incentive to participate originated in the community. Locals were able to control and manage productive resources, in the interests of their own families and the community [4-6].

CBT was not a tourism business, aiming to obtain maximum profits for investors. Rather, it was more relevant to the impact of tourism on community development and environmental resources. Thongma and Amnat [6] explained that CBT became an effective development guideline for tourism, as participation and $\mathrm{KM}$ among villagers were given importance, in order to maintain local resources and create a fair distribution of benefits to the villagers. CBT derived from the cooperation of a group of village representatives by applying their existing natural resources, local lifestyles, cultural perspectives, and environmental contexts to create a tourism itinerary [7-11]. The villagers participated in the management processes and all acquisitions. They were involved in guiding tours, providing homestay accommodation, arranging receptions and cultural performances, managing facilities and security, and running marketing, including public relations. The participatory management pattern, similar to that of a local travel agency, aimed to develop CBT, promote people's participation, and create self-reliance in a community [9-12]. 


\subsection{Benefits of CBT}

Tourism could contribute to several areas of negative impact on natural resources and local communities, with villagers rarely being the beneficiaries of such tourism. Thus, CBT was considered as an alternative form of tourism: not one which was a tourism business, trying to maximize profits for investors. Instead, it focused on the impact of tourism on the community and environment. CBT could not only help local villagers control the impact of tourism but also generate additional income and diversify the local economy. In addition, there were many environmental benefits from CBT, such as creating awareness and developing management skills, encouraging environmental planning and managing environmental problems [10-13]. In some cases, the government allowed local people and tourists to be the eyes and ears of environmental protection. Preserving local culture was another benefit of CBT. If communities knew the value of their traditions and culture, then wisdom and local knowledge could be transferred from generation to generation. In addition, cooperation with government and private sectors, close contact with tourists, and improving quality of life were also social benefits from CBT. The social cohesion, harmony, and cooperation that CBT enables could also enhance individual self-reliance, pride, and hope for the future. Furthermore, the money gained from CBT could also help improve the health and education of local people, which could go further towards alleviating poverty, decreasing population growth, and solving land distribution problems [14-18].

Moreover, CBT leads to the potential to decentralize the tourism industry by transferring decision-making to the community level, which leads to the empowerment of local communities and the development of local institutions, thereby providing a sense of ownership for community members, strengthening community identities and giving communities a sense of pride [19-21].

\subsection{Contexts of CBT}

The Social Development Institute of Chiang Mai University [7] claimed that there were four major contexts of CBT: tourism resources, local organizations and participation, management, and learning. Firstly, 'tourism resources' referred to the individual environmental and cultural uniqueness found in a community, including historical sites, ancient remains, indigenous knowledge, folk wisdom, and the specific competencies of villagers. 'Local organizations and participation' referred to a form of cooperation, among scholars, skilled people, and local representatives, in community development, community management, community consideration, community practices, and community performance evaluation. 'Management' referred to reasonable benefit allocation, the learning process among villagers and visitors, a mindset conscious of environmental protection, and the management of all tourism facilities and infrastructure [8-10]. Lastly, the 'learning' point focused on SWOT (internal/external contexts and conditions, comprising of Strengths, Weaknesses, Opportunities, and Threats) analysis of location, management pattern, and participation, to come up with creative tourism activities to provide tourists with an understanding of traditions and cultures. The four contexts had to work together for sustainable CBT development [1-6].

\subsection{CBT network}

As CBT provided advantages to communities and their villagers, it was more effective to set up CBT connection or association of members. A CBT network could create a powerful 
community and conduct business negotiations [5-7]. Members in the network could change attitudes and create valuable experiences, to their greater advantage. The CBT network originated from the leadership of one person or a small group of people and had to be supported by people holding the appropriate skills in managing financial and human resources. Thus, community leadership was vital for a CBT network and, in particular, it was an essential component in tourism development [14].

Active community participation was also a major factor in CBT networking. Participation in tourism planning and management meant that local people had a sense of responsibility for CBT, motivating them to make special efforts to control any negative impacts of tourism. It also ensured that CBT gave real support to the community and environment. Although community members participated right from the first stages of CBT management, the final decision might be made by the village headman and other community leaders, depending on community contexts [15].

\subsection{Establishment of a CBT network}

The establishment of a CBT network emerged as a solution to the negative effect of mass tourism; it could directly enhance tourism in a community because of the greater strength in negotiation and more tourism operations, both within and outside the community [16-18]. The establishment of a CBT network requires a local organization to manage tourism because the community needs a representative group to work with outside organizations and make arrangements with tourists and other stakeholders. To create a CBT network name or a brand recognition, the name of the CBT network should include the name of the community, and it can be founded within a community or within transboundary communities. CBT networks aim to focus on the participation of various community groups by giving them direct roles as committee members or shareholders [19]. In any case, CBT provides benefits indirectly to all, by contributing profits to a community fund. CBT includes many activities whose roles can be divided among the members of the CBT network, resulting in network effectiveness. Moreover, the network was mainly founded to provide an opportunity for community members, especially women, the elderly, and local youth, to show their abilities and working potential [20].

Generally, a CBT network can be established in seven steps: studying internal/external community contexts and conditions, searching for a network leader, promoting an awareness of associations and networks, developing activities to strengthen relationship levels, enhancing information systems, promoting cognitive processes among networks, and summarizing lessons learned [21].

\subsection{Development of a CBT network}

A community network could be enhanced through various means such as focus groups, KM, training courses, observations, etc. These techniques and activities aimed to provide unity, harmony, and participation, in order to distribute fair benefits and solve problems found in the communities [2]. A community network's success depended on participation from all community members, including stakeholders. Members worked on creating problem statements, development planning, being involved in performance, and taking part in performance evaluations. Thus, the role of community network leader was considered key to defining a vision for solving problems, developing the network, and distributing fair benefits among all stakeholders and villagers [3]. 
Another significant point of community network development was a feeling of ownership among community members. This would happen when local people played an active and participatory role in decision making, planning, planning implementation, performance evaluation, and the distribution of benefits. Also, the participation of all related stakeholders should begin from the start by involving people in the decision-making processes and management planning. They should share in the benefits of development programs and be involved in efforts to evaluate the network's performance [11-13].

However, at the start, CBT network enhancements were likely to have few participants, due to a lack of understanding about the network's objectives and missions. The CBT network had to keep opportunities for participation open to the community and not create rules that limited the capacities and resources of the community. Although it was quite difficult to ensure the direct participation of the entire network, the CBT network had to at least allow all members of the community to benefit indirectly from tourism. For the sustainable development of a CBT network, CBT performance had to be assessed by the network committee at least once a year, in order to enhance effectiveness, income, and benefits to the community $[4,7,10,12]$.

\subsection{Related studies}

Studies by $[2,3,6,8,14,17]$ revealed that CBT networking was very important for CBT development, as it contributed to the high value of local tourism, income distribution, and the working skills of local people. Successful CBT networking mainly relied on cooperation and human resource development, especially among villager leaders. The studies also revealed that the leaders lacked positive attitudes and professional management in the search for new markets and competitors, resulting in inefficient development and community achievement. In addition, the opinions of villagers, visitors, and all stakeholders needed to be considered, in order to provide a good quality of service and sustainable CBT enhancement. However, local people were satisfied with the decisions made by their leaders, who were fully respected by the villagers. Furthermore, those local villagers, who were the major recipients of tourism benefits, were more willing to participate in CBT activities than those who were minor recipients, receiving fewer benefits [8-13].

Although the related studies focused on CBT networking, their significance regarding networking, especially in border areas in northeastern areas of Thailand, was low. Therefore, it was important to determine CBT networking in the selected regions. All concepts, as well as related studies with findings, were then applied in the discussion of the findings for CBT networking development.

\section{METHODOLOGY}

\subsection{Framework of the study}

This study's framework was created, based on concepts of CBT, CBT contexts, and CBT networks, to identify and assess the established CBT network. The framework was then substantiated and analyzed to describe the findings.

According to the framework, Ban Saimoon and Ban Phosri were selected as both communities had been established as tourism communities for almost three years and they were only eight kilometers apart. Furthermore, the communities could connect to plenty of attractive destinations, both natural and cultural tourism routes, along the river Khong in the province [10]. 


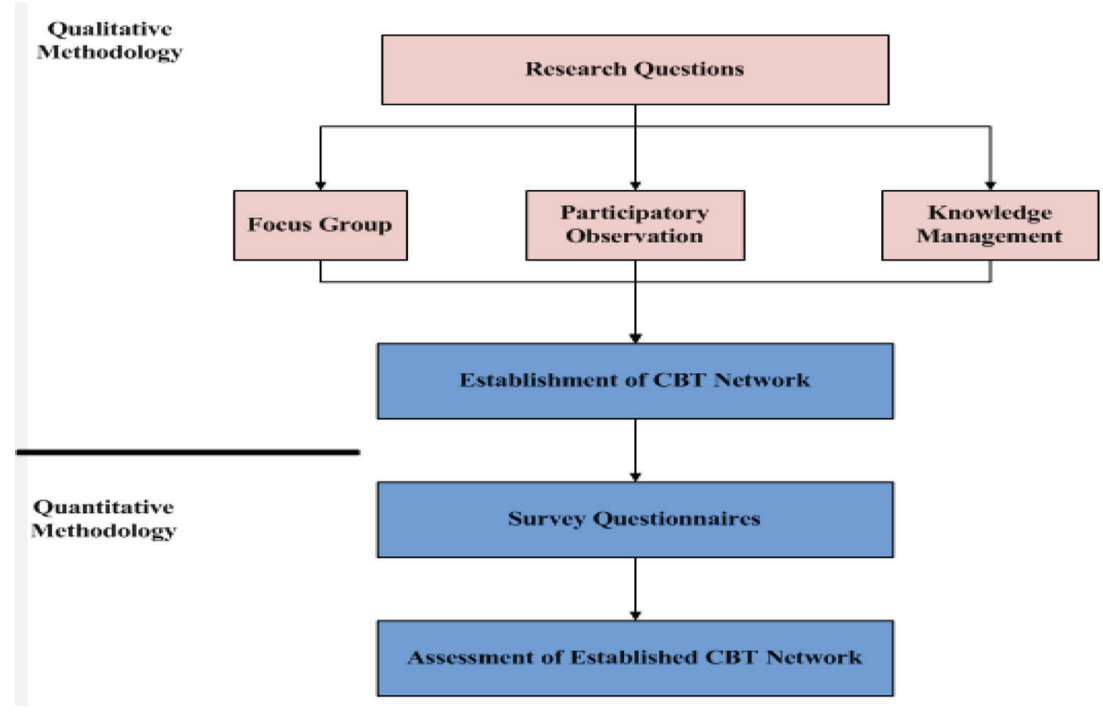

Figure 1: Study’s framework.

In this study, there were two population groups. The first was a total of 1,165 villagers; living in the communities, they were all considered stakeholders. Then, 30 participants, representing $15 \mathrm{CBT}$ representatives of each community, were chosen by nonprobability sampling. The second population group comprised a total of 250 visitors, who had used the services of the communities in 2015 [10]. Thirty of the visitors were later selected by probability sampling: 15 visitors to each village [15]. In total, this study was conducted for one year, from October 1, 2016 to September 30, 2017.

\subsection{Research instruments}

Two research tools were employed in this study, comprising qualitative and quantitative methods. Regarding qualitative methods, focus groups, participatory observation, and KM, proved by content validity, were employed. Additionally, survey questionnaires relating to satisfactory levels of CBT management, tested by content validity and index of item-objective congruence (IOC), were given to the respondents and constituted the quantitative methodology.

\subsection{Data collection and analysis}

All participants were invited to attend the three activities, consisting of focus group discussion, participatory observation, and knowledge management (KM) while some valuable opinions and suggestions, derived from these activities, were collected as a summary. Outside observation from the other CBT model in Ubon Ratchathani was mostly applied, to create a sample travel itinerary provided for 30 participants one day trip, visiting significant attractive destinations in the communities. All obtained data were applied to establish the CBT network. The respondents were then given the questionnaires to assess the performances of the established CBT network, consisting of four CBT contexts. Descriptive statistics, such as frequency, percentage, average, and standard deviation (SD), were used to analyze the questionnaires. All obtained data were then summarized as the study's results. 


\section{RESULTS}

The findings of this study could be explained to be consistent with the objectives as follows.

5.1 The establishment of a CBT network, as explained, in the areas concerned was presented as follows.

5.1.1 Studying internal/external community contexts and conditions

The focus group and KM activities were held on October 12, 2016 among 30 villagers, 15 from each community, in order to perform a SWOT analysis of their communities. The results demonstrated that the SWOT totals of the communities were similar. The communities' strengths and opportunities were then applied to make travel itineraries for visitors, as presented in Table 1.

Table 1: SWOT analysis of the two communities.

\begin{tabular}{|c|c|c|}
\hline Perspectives & Ban Saimoon & Ban Phosri \\
\hline $\begin{array}{l}\text { Strengths } \\
\text { - Natural resources } \\
\text { - Cultures and local } \\
\text { lifestyles } \\
\text { - Knowledge and folk } \\
\text { wisdom }\end{array}$ & $\begin{array}{l}\text { - Several islands with Moon } \\
\text { River flowing through } \\
\text { - Thai herbal forest } \\
\text { - Thai traditions and customs } \\
\text { - Northeastern cultures } \\
\text { - Thai herbal remedies } \\
\text { - Unique drum production } \\
\text { - Making of local brooms and } \\
\text { Thai funeral flowers } \\
\text { - Mushroom planting }\end{array}$ & $\begin{array}{l}\text { Occupational groups consid- } \\
\text { ered as the unique resources } \\
\text { of the community such as } \\
\text { handwork, cultural presen- } \\
\text { tations, herbal remedies, } \\
\text { traditional conservation, rice } \\
\text { production and packaging }\end{array}$ \\
\hline $\begin{array}{l}\text { Weaknesses } \\
\text { - Natural resources } \\
\text { - Cultures and local life- } \\
\text { styles } \\
\text { - Knowledge and folk } \\
\text { wisdom } \\
\text { - Community organiza- } \\
\text { tions } \\
\text { - Financial and fund man- } \\
\text { agement }\end{array}$ & $\begin{array}{l}\text { - Annual flooding } \\
\text { - Drought and fires in summer } \\
\text { season } \\
\text { - Lack of conservation of } \\
\text { traditions/cultures/wisdom/ } \\
\text { local knowledge among com- } \\
\text { munity youths } \\
\text { - Lack of established commu- } \\
\text { nity organizations } \\
\text { - Lack of community funds }\end{array}$ & $\begin{array}{l}\text { - Lack of knowledge of tour } \\
\text { guide and of service mind- } \\
\text { set among village leaders } \\
\text { - No tourism network/group } \\
\text { - Lack of conservation of } \\
\text { traditions/cultures/wisdom/ } \\
\text { local knowledge among } \\
\text { community youths } \\
\text { - Lack of established com- } \\
\text { munity organizations } \\
\text { - Lack of community funds }\end{array}$ \\
\hline $\begin{array}{l}\text { Opportunities } \\
\text { - Tourists and tourist } \\
\text { behaviors } \\
\text { - Connected tourism } \\
\text { routes } \\
\text { - Transportation } \\
\text { - Cooperation } \\
\text { - Government policies }\end{array}$ & $\begin{array}{l}\text { - Visitors' interest in Wat Don } \\
\text { Tard (a temple located in the } \\
\text { central island of the River } \\
\text { Moon) } \\
\text { - Beautiful attractions nearby } \\
\text { - Convenient access to destina- } \\
\text { tions through public roads } \\
\text { - Public bus services }\end{array}$ & $\begin{array}{l}\text { - Visitors' interest in herbal } \\
\text { massage and therapy } \\
\text { - Public bus services through } \\
\text { the community }\end{array}$ \\
\hline
\end{tabular}


Table 1: (Continued)

\begin{tabular}{lcl}
\hline Perspectives & Ban Saimoon & Ban Phosri \\
\hline Threats & - Walk-in tourists, resulting & The same results as Ban \\
- Tourists and tourist & in unprepared facilities and & Saimoon \\
behaviors & services & \\
- Connected tourism & - Damaged local roads to access \\
routes & significant destinations \\
- Transportation & - Many CBT communities in the \\
- Government policies & province leading to high level \\
& of competition \\
& - Complicated tourism support \\
& policy from local administra- \\
& tive organization \\
& - Lack of CBT assistance from \\
& outside organizations \\
\hline
\end{tabular}

5.1.2 Establishing a network and searching for a network leader

After the activities, a CBT network was established as 'Ban Saimoon and Ban Phosri CBT Network', with a total of 20 villagers as committee members, 10 from each village; Mr. Boonrak Somthep, the village headman and the chair of the CBT destination of Ban Saimoon, was selected as network chair. The network consisted of five sections: tourism operation, financial division, public relation, human resource development, and general affairs, coming into action on November 1, 2016.

\subsubsection{Promoting an awareness of associations and networks}

Monthly meetings were held, with at least two thirds of the total membership, for the planning and management of the network. The first meeting took place on November 29, 2016, for CBT training courses such as English communication skills, financial management, fundamental of tour guides, CBT management, and service mindset, with the cooperation of lecturers from Ubon Ratchathani University. The courses were arranged on the last day of the month, providing for CBT committees to create an understanding of CBT and networking. At the beginning of 2018, due to the lack of assistance from outsiders, the network will request budgets and greater cooperation from government/outside

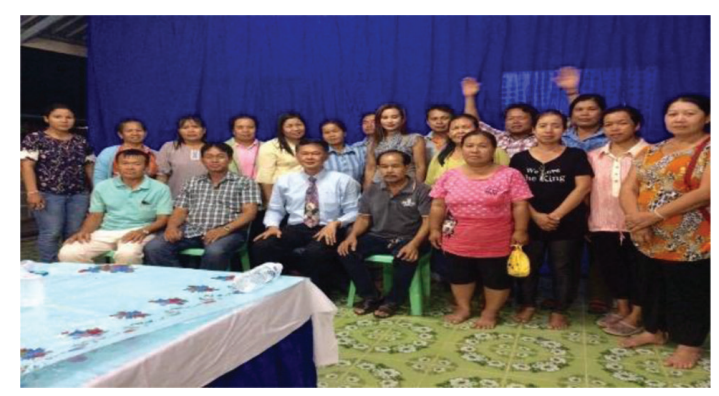

Figure 2: The established CBT network. 
organizations, to enhance the tourism infrastructure for more convenient access to tourism attractions and satisfactory services.

\subsubsection{Developing activities and relationship levels}

Travel itineraries, presenting the strengths and opportunities of unique destinations, were created for presentation to the visitors. Villagers of the two communities, especially women and local youths, took part by performing as tour guides and applying their residences as home stay accommodation to serve walk-in visitors. Two shops, selling souvenirs and handicrafts, were opened so that the villagers could earn extra income, which was separate from the income generated from tourism activities. As CBT was operated and managed as a part of the communities, a CBT cooperative will be established in 2019, in order to distribute tourism benefits as widely as possible; every household will be a member of the cooperative, and the dividend will be paid annually.

\subsubsection{Enhancing information system}

A community tourism database, a public relation center, a TV program of local tourism resources via local TV channels, and network communication via media channels (Facebook Fan Page and Line) were created, and local educational institutes cooperated. The center of the information system was in the network office in Ban Saimoon.

\subsubsection{Promoting cognitive processes among networks}

The network established cooperation and commitment with two CBT destinations, as CBT models in the province, for exchanging development ideas and CBT knowledge sources, by arranging outside observations in March and June 2017. The advantages and strengths of the CBT model were applied and implemented in the communities such as ideas for the establishment of occupational groups and the arrangement of leadership/administration trainings, and public hearing activities.

\subsubsection{Summarizing of lessons learned}

On September 1, 2017, the network meeting was arranged, and a total summary of information from sections 5.1.1 to 5.1.6 collected by the division of general affairs, was applied. Information on the total turnovers, overall performances, problems, solutions, and recommendations would be discussed for better management in the next year.

\subsection{CBT network performances}

The assessment, derived from survey questionnaires, was as indicated in the following Table 2.

The table's result indicates that the respondents were satisfied with the natural resources and community culture and the CBT learning found in the communities because all attractive resources were presented in tour programs to the visitors, with continued tour-guide training courses arranged for villagers and volunteers. The respondents were satisfied with the English communication and service mindset courses arranged monthly by the network, for promoting members' learning. Tourists also had opportunities to learn about local wisdom and traditional knowledge from the locals, and villagers strongly agreed that their community offers local lessons to tourists and the tourists had the opportunities to exchange knowledge with local people. However, the community organizations, people's participation, 
Table 2: Assessment of the established CBT network in the two communities.

\begin{tabular}{llll}
\hline CBT contexts & Average & Standard deviation & Meaning \\
\hline $\begin{array}{l}\text { 1. Natural resources and community } \\
\text { cultures }\end{array}$ & 3.93 & 0.62 & High \\
$\begin{array}{l}\text { 2. CBT learning within the network } \\
\text { 3. Community organizations and }\end{array}$ & 3.69 & 0.72 & High \\
$\quad 3.41$ & 0.50 & Medium \\
$\begin{array}{l}\text { 4. CBT management } \\
\text { Total }\end{array}$ & 3.04 & 0.42 & Medium \\
\hline
\end{tabular}

and community management were located at the 'fair' level, as network members did not have any authority or official status. Consequently, when conflicts occurred, other villagers who disagreed might not follow or believe in the leaders' ideas, and sometimes decisions were made by the leader without the participation of members. Additionally, as none of them was a formal CBT member, it was difficult to receive reasonable government support and outside allocations. As a consequence, they had a less positive attitude towards CBT networking and management.

Overall, the respondents believed that the established CBT network run by community members, with the major aim of managing the relationships among residents, resources and visitors, would lead to successful management in the future. Furthermore, the network could facilitate group processes to build the cooperation, skills, knowledge and commitment among community members, so that they could manage tourism in a sustainable manner.

\section{DISCUSSION AND CONCLUSION}

The results were derived from the analysis of interviews with villagers, to identify the establishment and evaluation of CBT networking in the two communities. In order to create a CBT network that meets the villagers' needs, the entirety of the contexts and environments in the communities must be considered. The results clearly demonstrated that CBT-network development could be achieved when the network members and villagers realized their responsibilities and fully appreciated their natural and cultural resources. However, support from government and private organizations remained significant. Mostly, local communities receive assistance from public agencies, private sectors, NGOs and academic institutions, in terms of financial and technical support. The researcher noticed that CBT in the two communities could not be successful without external assistance and the CBT network could not exist with limited budgets. The Thai government and Thai society as a whole should accept the right of local people to participate in CBT activities, since CBT is going to be big business in Thailand. However, the establishment of CBT was a good step towards creating the potential for empowering the community and controlling their resources and tourism activities to help them develop their knowledge and management skills to cope with this new community business.

Another interesting point was that an internationally successful CBT network might not be adapted easily and completely within the Thai context, due to the differences in communities and environments. Typically, in international contexts, CBT has been employed as a tool for poverty solution: using tourism as a source of additional income for local people 
$[10,20,21]$. On the other hand, the implementation of CBT in Thailand was not in the expectation of economic benefits from tourism; it was a preferred method to expand and preserve the cultural heritage and natural sustainability. Thus, this study attempted to explain benefits that local people could receive from implementing CBT and CBT networking. The results would help policy makers develop appropriate strategies for the conditions and problems in local villages.

The findings were consistent with those of [7-11], in that a network provided highquality cooperation among both internal and external organizations, including stakeholders such as clients, suppliers, investors, competitors, etc. Networks were widely applied to increase the quality and effectiveness of organizations' products and services. The findings also corresponded with those of $[3,8,12,16]$, stating that well-prepared entrepreneurs depended on a network's performance and association. In tourism organizations, networking gave importance to maximizing the profits and benefits derived from the tourism resources of communities, and appealing destinations found in tourism areas, including unknown destinations, had to be considered for presentation in travel itineraries, in order to meet a wide variety of customers' needs and enhance the infrastructure of the areas. In conclusion, CBT networking was relevant to all stakeholders in a community and other villages aiming to maintain competitive business opportunities. Secondly, the findings also showed that, to achieve sustainable tourism and business competitiveness, communities had to adapt themselves, establish a network, use up-to-date information, and focus on tourism association and customer relationship management. Additionally, CBT networks can help economic and community development, in areas where the territory is the most valuable resource [20-25].

\section{ACKNOWLEDGEMENT}

The study was conducted with the full participation and assistance of tourists, villagers, and all stakeholders in Ban Saimoon and Ban Phosri communities. I sincerely thank my colleagues in the Faculty of Liberal Arts, Ubon Ratchathani University, for their guidance and encouragement to finish this study. Also, I would like to express my gratitude to Mr. Robert Brundage for methodological suggestions and to Ubon Ratchathani University for financial support.

\section{REFERENCES}

[1] Sarobol, S. et al., Community-Based Tourism: Concepts and Experiences in Northern Region of Thailand, Vanida Press: Chiang Mai, 2006.

[2] The Thailand Community Based Tourism Institute, Community Based Tourism, Thailand Research Fund (TRF): Chiang Mai, 2003.

[3] Vilairat, N. \& Boonsa-ard, W., A Study of Possibility Concerning Community-Based Tourism Management in Ban Sai Moon, An Independent Study, Faculty of Liberal Arts: Ubon Ratchathani University, 2015.

[4] Office of Ubon Ratchathani Community Development, Assistance Project on Occupational Development of Office of Ubon Ratchathani Community Development, Office of Ubon Ratchathani Community Development, 2016.

[5] Halstead, L., Making Community-Based Tourism Work: An Assessment of Factors Contributing to Successful Community-Owned Tourism Development in Caprivi, Namibia. DEA Research Discussion Paper. Tamsin Savage., ed. 60 (July), Ministry of Environment and Tourism: Windhoek, Namibia, 2003. 
[6] Suansri, P., Manual of Community-Based Tourism Management, Tourism Project for Lives and Natures: Bangkok, 2003.

[7] Thongma, W. \& Amnat, P., Outcomes of Tourism Activity Management towards People Living in Mae Ram, Mae Rim District, Chiang Mai, Division of Agricultural Promotion, Mae Jo University: Chiang Mai, 2004.

[8] Friefenberg, R., Operating a successful ecotourism enterprise: the case of Siam Safari in Phuket, Thailand. In Ecotourism for Forest Conservation and Community Development. RECOFTC: Bangkok, 1998.

[9] Social Research Institute of Chiang Mai University, Manual of Community Based Tourism and Home Stay Accommodations, Nopburi Printing House: Chiang Mai, 2005.

[10] Hassan, S., Determinants of market competitiveness in an environmentally sustainable tourism. Journal of Travel Research, 37(3), 2000.

[11] Pootjorn, J., et al., Establishment of Community-Based Tourism Networks in Northeastern Region of Thailand, Faculty of Business Administration and Management: Ubon Ratchathani Rajabhat University, 2006.

[12] Thongho, R., et al., Networking of Community-Based Tourism by Participatory Action Research (PAR) in Provinces Located in Central Region of Thailand. Complete Research Study: Ramkhamhaeng University, 2008.

[13] Hoof, A., Analysis of the Critical Success Factors of Community Based Tourism: A Tourism and Conservation Project in the Central Danube Floodplains. Master's Thesis, The Netherlands Institute of Tourism and Transport Studies, 2006.

[14] Somthep, B., Information of Ban Sai Moon and Visiting Books. Ban Sai Moon, Sai Moon Sub-district, Phiboon Mangsahan: Ubon Ratchathani, 2016.

[15] Yamane, T., Statistics: An Introductory Analysis, Harper International Edition: Tokyo, 1973.

[16] Karnjanarangseenan, K., Establishment of Networks for Development. Division of Research and Development, Community Development Department: Bangkok, 2007.

[17] Campfens, H., Community Development around the World: Practice, Theory, Research, Training, University of Toronto Press: Toronto, 1997.

[18] Clarke, J., Effective marketing for rural tourism in aspects of tourism. In Rural Tourism and Sustainable Business, eds. D.R. Hall, I. Kirkpatrick \& M. Mitchell, Cromwell Press: Clevedon, 2005.

[19] Decrop,A., Trustworthiness in Qualitative Tourism Research: Ontologies, Epstemologies and Methodologies, eds. J. Phillimore \& L. Goodson, TJ International: London, 2004.

[20] Dickman, S., Tourism and Hospitality Marketing, Oxford University Press: Melbourne, 1999.

[21] Dunn, S., Toward Empowerment: Women and Community-Based Tourism in Thailand. Master's Thesis, University of Oregon, 2007.

[22] Eurblarp S., Ecotourism Policy in Thailand: Linking Green Productivity to Ecotourism, University of Queensland Printery: Brisbane, 2002.

[23] Mason, P., Tourism Impacts, Planning and Management, 2nd edn., ButterworthHeinemann Publications: Burlington, 2008.

[24] Mathbor, M., Effective Community Participation in Coastal Development, Lyceum Books: Chicago, 2008.

[25] Inskeep, E., Tourism Planning: An Integrated Sustainable Development Approach, Van Nostrand Reinhold: New York, 1991. 